No. 13

The Complementarity

between Endogenous Protection

and Direct Foreign Investment

Laixun Zhao

February 1995

Department of Economics

Otaru University of Commerce 


\section{THE COMPLEMENTARITY BETWEEN ENDOGENOUS PROTECTION AND DIRECT FOREIGN INVESTMENT}

Laixun Zhao

Otaru University of Commerce

This paper studies the endogenous relationship between direct foreign investment (DFI) and trade restriction. A domestic labor union interested in both employment and wages bargains with a foreign firm and lobbies against foreign imports. By endogeneizing the wage rate and incorporating resourceusing lobbying, we show that more DFI results in higher lobbying efforts and lower imports under fairly general conditions, i.e. a reversal of quid pro quo DFI. We also conduct comparative statics analysis on wages and lobbying efforts.

(JEL Classification: $F 1, F 2, J 5)$

(Key Words: Lobbying, Endogenous Protection, Quid Pro Quo DFI)

Correspondence: Department of Economics, Otaru University of Commerce, Otaru, Hokkaido 047, JAPAN

Fax: 81-(0134)-22-0467

Email: zhao@canal.otaru-uc.ac.jp

*I wish to thank E. Dinopoulos, J. Itaya and K. Yamamoto for very helpful discussions and comments. I am solely responsible for any remaining errors. 


\section{Introduction}

Since Bhagwati (1985) introduced the concept of quid pro quo direct foreign investment (DFI), it has attracted considerable interest ${ }^{1}$. Quid pro quo DFI occurs when "the foreign firm invests in period $1 \ldots$ with a view to influencing favorably the threat of protection in period 2 later and thereby making more profits by keeping markets open. Thus, the aim of such DFI is to defuse the protectionist threat (Bhagwati, 1987)." In particular, it has been shown by Wong (1989) and Dinopoulos and Wong (1991) that increases in DFI by the foreign firm will decrease future protectionist threats against foreign imports in the host country. On the other hand, based on the assumption that quid pro quo DFI is successful in defusing future protectionist threats, Bhagwati et al. (1987) and Dinopoulos (1989, 1992) analyzed respectively the optimal trade policies by the importing country and the host country under different market structure.

This paper studies the relationship between DFI and endogenous protection created by union lobbying. However, our results contrast those in the literature. We analyze a three stage game between a foreign firm and a domestic labor union. In order to compare results, we follow the conventional quid pro quo DFI structure by assuming that the foreign firm acts as a Stackelberg leader in choosing DFI in the first stage. In the second stage the labor union lobbies the domestic government for protection against foreign imports. The wage rate is negotiated between the firm and the union in the third stage.

Our model differs from the existing literature in two aspects. First, we

1 Bhagwati, Dinopoulos and Wong (1992) provide a very good review of the literature. 
endogeneize the wage rate; second, we let the foreign parent firm (not the subsidiary) bargain with the labor union for wages. These two modifications drive a complementarity relationship between DFI and import restriction. We show that if import restrictions depend on the resource-using lobbying by the labor union, then an increase in DFI raises the union's marginal benefit of lobbying through the wage effect, but leaves the marginal cost unchanged. The wage effect of lobbying is positive. It increases if the firm's marginal profit of exports decreases. An increase in DFI reduces the marginal profit of exports and thus makes the wage effect of lobbying more positive. Consequently more DFI results in higher lobbying efforts and lower imports allowed. Hence quid pro quo DFI does not occur. This result holds for very general demand conditions.

We also consider an alternative game structure. In an extension, we combine the first two stages of the previous model into one stage and reduce the game to two stages. Thus DFI is not of the quid pro quo type since the foreign firm is not a first mover. We obtain similar results: DFI increases union lobbying.

Our results are consistent with the fact that many firms are reluctant to undertake DFI, even with imminent danger of increased trade restrictions. In a comprehensive study of the U.S. automobile industry, Nelson (1994, pp3-4) describes how the UAW (United Auto Workers) as well as the U.S. government tried to induce Japanese investments in the U.S. since the mid-1970s, yet the Japanese producers were not responsive for quite some time, which was part of the reasons that led to the imposition of the auto VERs in 1981.

There is no need to elaborate the importance of endogeneizing the wage rate whenever a labor union is involved in the negotiations. The two most 
common approaches to model union objectives both include employment as well as wage rate as arguments (see Oswald's survey paper, 1987). In an empirical study, Clark and Oswald (1993) even show that unions care more about wages than employment, which is widely believed to be true by many other researchers.

On the other hand, the inclusion of the foreign parent firm in the bargaining game arises from the fact that the foreign firm maximizes its total profits from different branches. In the present model, letting the subsidiary (not the parent) firm bargain with the union is inappropriate because an increase in union lobbying reduces the foreign firm's total profits but increases that of the foreign subsidiary in the host country. Further, it would take away one of the most important advantages of the multinational firm (MNF) versus a national firm-mobility. If the union strikes in the host country, the MNF can move at least a portion of its production to the foreign country. Thus, the present paper shows that participation in bargaining by the foreign parent firm improves its threat point and lowers the negotiated wage rate. There is also abundance of evidence in support of this point (see Bergsten et al, 1978).

The present paper extends the analysis of but is more general than Wong (1989), Dinopoulos and Wong (1991) and Dinopoulos (1992). Wong (1989), Dinopoulos and Wong (1991) model a union which lobbies to eliminate unemployment while fixing the wage rate at the competitive level. Our model yields their main result if the union is completely uninterested in wages. Dinopoulos (1992) shows that quid pro quo DFI occurs if the union is employment oriented, but the negotiation for wages involves the foreign subsidiary instead of the parent firm and he abstracts from incorporating resource-using lobbying. 
Section 2 develops the basic assumptions of this paper and analyzes the three stage game. Section 3 proves the same complementarity result in a two stage game. Section 4 concludes.

\section{A three-Stage Bargaining Game with Lobbying}

Consider a foreign firm which can produce in both the foreign and the host countries but sells only in the latter, and a host country labor union whose members are employed by the foreign subsidiary. The host country government imposes a VER on the foreign firm in response to the lobbying pressure of the labor union. We assume that in the host country, output is produced with labor alone with an input-output coefficient equal to one by choice of units. Hence output is equal to the level of employment. In the foreign country, the foreign firm has decreasing marginal cost of production. Transportation cost is zero. Thus in the absence of trade restrictions, the foreign firm produces in its own country and exports abroad. It undertakes DFI only if the host country imposes restrictions against imports. We will argue that in our model such DFI only hurts the foreign firm.

The game is set up as follows. In the first stage, the foreign firm chooses the level of DFI, anticipating the protectionist pressure in the host country. Then given the level of DFI, the labor union lobbies for the level of VER in the second stage. In the third stage the union and the firm determine the wage rate through a cooperative Nash bargaining process. To ensure subgame perfection, the game is solved backwards. ${ }^{2}$

2 To compare results with the quid pro quo DFI literature, we would like output to be determined before the wage is negotiated. Adopting the efficient bargaining framework introduced by McDonald and Solow (1981) would result in simultaneous determination of output and the wage, which would exclude the possibility of the Stackelberg leader position of the foreign firm. In addition, the 
Denote $X$ the level of DFI by the foreign firm, which is also equal to union employment, and $Y$ the level of imports, which is a function of lobbying $L$ such that $Y=Y(L)$, with $Y_{L}<0$ and $Y_{L L}>0$. This implies that as lobbying pressure increases, import restrictions become more strict, i.e. the level of imports permitted under the VER is lowered ${ }^{3}$. The foreign firm's total profit is a sum of its profits from DFI and exports, which can be written as ${ }^{4}$

$$
\Pi(W, L, X)=(P-W) X+P Y-T(Y)
$$

where $P=P(X+Y)$ is the inverse demand, $W$ is the negotiated wage rate in the host country and $\mathrm{T}(\mathrm{Y})$ is the cost of producing $\mathrm{Y}$ in the foreign country, with $T_{Y}>0$ and $T_{Y} \leq W$ for $Y \leq Y^{*}$, where $Y *$ is the level of imports under free trade. This implies that in the absence of trade restrictions, DFI does not occur since the marginal cost of production is smaller in the foreign country.

We assume that the labor union maximizes a more general utility function than Dinopoulos and Wong (1991). Specifically we adopt a modified Stone-Geary type function ${ }^{5}$ :

$$
U=(W-\bar{W}){ }^{\theta} X^{\gamma}[C(L)]^{-0}
$$

Brander and Spencer (1988) bargaining game which assumes that the wage is negotiated first and then the firm determines the output unilaterally is not appropriate in our framework because it would imply that decisions to invest in a foreign country were more flexible than wage contracts. Consequently, the context of quid pro quo DFI gives rise to a game where wages are negotiated
after the determination of DFI.

3 See Findlay and Wellisz (1982) for a formulation of this process in general equilibrium where the level of protection (tariff in their case) depends on
lobbying resources.

${ }^{4}$ In principle, profits should incorporate the cost of capital explicitly, since DFI is not free. Then due to the assumption that the input-output coefficient is one, one has $I=(P-W-R) X+P Y-T(Y)$ where $R$ is the capital rental. Dinopoulos (1992) shows that the analysis is robust.

5 This utility function is log separable, in which case it is similar to an alternative specification of the union utility. Oswald (1985) discusses the differences between the two specifications. 
where $\bar{W}$ is the competitive wage in the outside goods sector, hence $W-\bar{W}$ is the wage differential the union obtains through negotiation; and $\mathrm{X}$ is union employment. Modeling both wage differentials and relative employment enables us to study the union's different orientation toward the two. C(L) represents the cost of supplying lobbying effort, $L$, which is a productive input (for protection) with direct disutility to the union. ${ }^{6}$ We assume $\delta>0, C_{L}>0, C_{L L}>$ 0 and $U($.$) is concave in its arguments { }^{7}$. One could express the objective of the union as maximizing expression (2) for $\delta=0$, net of lobbying costs (see Wong, 1989). However, by introducing lobbying effort directly into the union's utility, the analysis is simplified. $\theta, \gamma$ correspond respectively to the wage and employment elasticity of the union's utility.

\subsection{The Determination of the Wage Rate}

In the last stage of the game the union and the foreign firm determine the wage rate through a cooperative Nash bargaining game, taking $\mathrm{X}$ and $\mathrm{L}$ as given. The solution is obtained by maximizing the generalized Nash product, which is a product of the payoff functions for the two players, net of opportunity costs as measured from the threat points.

If bargaining breaks down, the foreign subsidiary produces zero output in the host country and employment and utility of the union are zero. However the foreign firm still produces in the foreign country. Its threat point is the profit from exporting to the host country without DFI, which can be written as

$$
\Pi_{0}(Y)=P_{0} Y-T(Y)
$$

6 This formulation where cost is introduced in the utility function is standard in the principal-agent literature (see Holmstrom, 1979).

7 See condition (11). 
where $P_{0}=P(Y)$, since $X=0$. It is reasonable to assume that union strikes do not affect the level of union lobby. This will keep lobby and hence imports the same for $I$ (regular profit) and $\Pi_{0}$ (threat point payoff). The optimal level of lobby is determined by maximizing the union's utility in the second stage, to be discussed in the next subsection. Thus $\Pi_{0}$ is treated as a constant here. However Nash bargaining implies that threat points, which are Pareto inefficient, are not reached.

With the above descriptions, we can write the generalized Nash bargaining product as

$$
G(W)=U^{\alpha}\left(\Pi-\Pi_{0}\right)^{1-\alpha}
$$

where $a$ is the relative bargaining weight of the union.

Substituting (1), (2), (3) into (4) yields

$$
G(W ; L, X, O)=\left\{(W-\bar{W})^{\theta} X^{\gamma} C(L)^{-\delta}\right\}^{\alpha}\left\{(P-W) X+P Y-T(Y)-\Pi_{0}\right\}^{1-\alpha}
$$

where $O=\left(\alpha, \theta, \gamma, \delta, \bar{W}_{,} \Pi_{0}\right)$. Maximizing $G($.$) with respect to the wage W$, the first order condition is obtained as follows:

$$
\frac{\alpha \theta}{W-\bar{W}}-\frac{(1-\alpha) X}{\Pi-\Pi_{0}}=0
$$

The first term on the left hand side of (6) is the gains for the union and the second term the losses to the firm as the negotiated wage rate increases.

Rearranging condition (6), we obtain

$$
W=K(P+V)+(1-K) \bar{W}
$$

where $K=\alpha \theta /(\alpha \theta+1-\alpha)$, and $V=\left(P Y-T-\Pi_{0}\right) / X$ is negative because $P<P_{0}$ for each level of $Y$. Condition (7) states that the negotiated wage rate is a convex combination of $\mathrm{P}$ and $\bar{W}$ plus a negative value. It is lower than that in Dinopoulos (1992), where only the foreign subsidiary participates in bargaining and hence $\mathrm{V}$ does not appear. In the present model, participation in bargaining 
by the foreign parent firm improves its threat point by $\Pi_{0}$ and lowers the negotiated wage rate by $\mathrm{KV}$.

Differentiating $W$ with respect to respective variables, we obtain the following comparative statics results (subscripts denote partial derivatives).

$$
\begin{aligned}
& W_{\alpha}=\theta(P-\bar{W}) /(\alpha \theta+1-\alpha)^{2}>0 \\
& W_{\theta}=(1-\alpha)(P-\bar{W}) /(\alpha \theta+\overline{1-\alpha})^{2}>0 \\
& W_{\bar{W}}=1-K>0 \\
& W_{\Pi_{0}}=-K / X<0
\end{aligned}
$$

where $Y_{L}<0$ as assumed. All the above partial derivatives have expected signs, i.e., the negotiated wage rate increases with an increase in the union bargaining power, or in the union's preference toward wages, or in the outside sector wage; while it decreases if the firm's threat point improves.

Union lobby has a positive effect on the negotiated wage, ceteris paribus. To see this, differentiating condition (7) with respect to $L$ yields

$$
W_{L}=\left(K Y_{L} / X\right)\left(\Pi_{Y}-\Pi_{O_{Y}}\right)>0
$$

where $\Pi_{Y}-\Pi_{0 y}=\left[P+(X+Y) P^{\prime}\right]-\left(P_{0}+X P_{0}^{\prime}\right)$ for the same level of $Y$, i.e. a differential between the regular marginal revenue and the marginal revenue at the threat point. Note $\mathrm{P}_{0}=\mathrm{P}(\mathrm{Y})$ is the price at the threat point. For downward sloping inverse demand curves, $\left[P+(X+Y) P^{\prime}\right]-\left(P_{0}+X P_{0}^{\prime}\right)<0$, since the total output associated with the former is bigger than that with the latter by $\mathrm{X}$, the amount of DFI.

Intuitively, condition (8e) says that as lobbying effort is increased by the union, the foreign firm's total profit decreases, but its threat point payoff decreases even more. Thus the payoff improvement above the threat point for the foreign firm, $\Pi-\Pi_{0}$, is increased and hence it is less willing to risk a 
breakdown in bargaining. This puts the firm in a less aggressive position and in turn yields to the union in terms of the negotiated wage in the bargaining game.

Why then does union lobby reduce the firm's regular profit more than its threat point payoff? The answer is very simple; that is, the firm could move production to the host country with $\Pi$, but not with $\Pi_{0}$.

Note that if the foreign subsidiary participated in bargaining instead of the parent firm (as in Dinopoulos, 1992), then the firm's threat point payoff is zero. An increase in lobby would not change the subsidiary's threat point. However, it would increase the subsidiary's regular profit, since a portion of the reduced imports (caused by increased lobby) is replaced by increases in DFI.

Differentiating the negotiated wage $W$ with respect to DFI $X$ yields

$$
d W / d X=W_{X}+W_{L} d L / d X
$$

where $W_{X}=(K / X)\left[(X+Y) P^{\prime}-V\right]$, and $V<0$ as given in equation (7). At this point, the sign of condition (8f) can not be determined since the sign of $\mathrm{dL} / \mathrm{dX}$ is not known yet. We will come back to this condition in the next subsection.

\subsection{DFI, Lobbying and Protection}

In the second stage of the game the labor union lobbies the government to determine the level of a VER. Substituting the negotiated wage rate in (7) into the union's utility function, we can express the latter in terms of employment and lobbying efforts, i.e.

$$
U(L ; X, O)=(K \bar{\Pi})^{\theta} X^{\gamma-\theta}[C(L)]^{-\delta}
$$

where $\bar{\Pi}=(P-\bar{W}) X+P Y-T(Y)-\Pi_{0}$ is positive.

We now analyze the determination of the union's equilibrium level of 
lobbying and the VER. Maximizing (9) with respect to $L$ yields

$$
\frac{\theta \bar{\Pi}_{L}}{\bar{\Pi}}-\frac{\delta C_{L}}{C}=0
$$

where $\theta \bar{\Pi}_{L} / \bar{\Pi}=\theta W_{I} /(W-\bar{W})>0$ is the marginal benefit of lobbying. It comes from the wage effect of lobbying, shown in condition (8e). An increase in union lobby efforts raises the negotiated wage rate. The second term is the marginal cost. The union maximizes utility by equating marginal benefit to marginal cost, from which one could implicitly solve the equilibrium level of union lobbying, $L^{*}$, as a function of DFI $X$ and the parameters $O$.

To characterize the optimal level of union lobbying more clearly, define

$$
\begin{aligned}
& M B(L)=\frac{\theta \bar{\Pi}_{L}}{\bar{\Pi}} \\
& M C(L)=\frac{\delta C_{L}}{C}
\end{aligned}
$$

where $M B(L)$ and $M C(L)$ correspond respectively to the marginal benefit and marginal cost of lobbying. Figure 1 plots the two. The former is negatively or less positively sloped than the latter by concavity of the union's utility function, while the latter is positively sloped if we rule out increasing returns to lobbying. The intersection of the two curves determines the equilibrium level of lobbying the union undertakes, $L^{*}$, and hence the VER the foreign firm has to face, $Y$.

Next we analyze the impact of DFI on the marginal benefit and marginal cost of lobbying. Differentiating the latter two with respect to DFI yields respectively

$$
\begin{aligned}
& \frac{\partial M B}{\partial X}=\frac{\theta Y_{L}}{\bar{\Pi}^{2}}\left\{\bar{\Pi} \bar{\Pi}_{Y X}-\bar{\Pi}_{Y} \bar{\Pi}_{X}\right\} \\
& \frac{\partial M C}{\partial X}=0
\end{aligned}
$$


where $\bar{\Pi}=(P-\bar{W}) X+P Y-T(Y)-\Pi_{0}$ is positive. In deriving condition (12a), $\bar{\Pi}_{\Sigma}=Y_{L} \bar{\Pi}_{Y}, \bar{\Pi}_{L X}=Y_{L} \bar{\Pi}_{Y X}$ were used.

Condition (12b) is obvious since lobbying cost does not depend on DFI endogenously. Condition (12a) implies that DFI affects the marginal benefit of lobbying through the wage effect. We can rewrite it in the following elasticity form

$$
\frac{\partial M B}{\partial X}=\frac{\theta Y_{L}}{\overline{\bar{\Pi}}^{2}}\left\{\frac{\partial \bar{\Pi}_{Y}}{\partial X} \frac{X}{\bar{\Pi}_{Y}}-\frac{\partial \bar{\Pi}}{\partial X} \frac{X}{\bar{\Pi}}\right\}
$$

which says that DFI increases the marginal benefit of lobbying if the first elasticity outweighs the second. We can prove that this hold true under fairly general conditions. To see this, we need the expression in braces negative in condition (12a), since $Y_{L}<0$. Define

$$
\Delta=\bar{\Pi} \bar{\Pi}_{Y X}-\bar{\Pi}_{Y} \bar{\Pi}_{X}
$$

Substituting the negotiated wage into (1) we have $\bar{\Pi}=\left(\Pi-\Pi_{0}\right) /(1-K)$, where $K$ is given in condition (7). Then $\bar{\Pi}_{x}=\Pi_{X} /(1-k)$ and $\bar{\Pi}_{Y X}=\bar{\Pi}_{X X}=\Pi_{X X} /(1-k)$, since $\Pi_{0_{x}}=0$. And from condition (8e), we also have $\overline{\boldsymbol{I}}_{Y}=\left(\Pi_{Y}-\Pi_{0}\right) /(1-K)<0$. Substituting these into condition (13) to obtain

$$
\Delta=\left[1 /(1-K)^{2}\right]\left\{\left(\bar{\Pi}-\Pi_{0}\right) \Pi_{X X}-\left(\Pi_{Y}-\Pi_{0}\right) \Pi_{X}\right\}
$$

Appendix A proves that for inverse demand functions of the following form

$$
P=a-(X+Y)^{i}, \quad P_{0}=a-Y^{i} \quad(a>0, \quad i=1,2, \ldots, n)
$$

condition (13') is negatively signed.

To interpret the above results, let us first see the effects of the marginal profit of exports on the wage effect of lobbying. Differentiating condition (8e) with respect to $\Pi_{Y}$ yields

$$
\frac{d W_{L}}{d \Pi_{Y}}=K Y_{L} / X<0
$$


Condition (15) implies that since the union lobbies to decrease imports and as a consequence the foreign firm's profits, if the marginal profit of exports increases given the level of lobbying, then the firm is more profitable for the same level of exports and thus lobbying is less effective in terms of raising the wage rate.

Now DFI will decrease the marginal profit of exports $\Pi_{Y}$, since $\Pi_{X X}=\Pi_{X X}<0$. As a consequence, an increase in DFI $X$ will push up $W_{L}$ from condition (15). Since DFI only affects the marginal benefit of lobbying from conditions (12a) and (12b), and through the wage effect of lobbying $W_{L}$, it is easy to see why condition (12a) is positively sloped; that is, an increase in DFI will trigger more lobbying from the union because it increases the marginal benefit of lobbying (by making the wage effect of lobbying more positive). This is shown in figure 1 , where curve $M B$ shifts up to $M \hat{B}$, but curve $M C$ does not shift. The optimal level of union lobbying is $\hat{L}$, with $\hat{L}>L^{*}$. Since $\mathrm{Y}_{\mathrm{L}}<0$, we thus have $\frac{d Y}{d X}<0$; that is, DFI and endogenous import restrictions are complements in that an increase in DFI lowers the level of imports allowed.

This is where our main results differ from Wong (1989) and Dinopoulos and Wong (1991), which correspond to the case $\theta=0$, i.e. the union is completely uninterested in wages, and hence there is no wage effect of lobbying. Dinopoulos (1992) recognizes the possibility that condition (12a) can be positive, but he abstracts from it and studies the effects of quid pro quo DFI.

Now we return to condition (8f), to discuss the effect of DFI on the negotiated wage rate. We still can not say whether $W_{X}$ is positive or negative. However, since we have shown that $d L / d X>0$, the effect of DFI on the wage rate through union lobbying [the second term in (8f)] is positive. 


\subsection{The Determination of optimal DFI}

In the previous subsections, we have solved the last two stages of the game and determined the negotiated wage, the optimal level of lobbying from the labor union and hence the VER. Now we turn to the first stage of the game, in which the foreign firm maximizes profits by choosing the level of DFI.

Substituting the negotiated wage and the optimal union lobbying into equation (1), we obtain the foreign firm's total profit as a function of DFI X

$$
\Pi(X ; O)=(1-K)\{(P-\bar{W}) X+P Y(.)-T(Y(.))\}+K \Pi_{0}(.)
$$

Differentiating with respect to $\mathrm{X}$ yields

$$
(1-K) \Pi_{X}+(1-K) \Pi_{Y} d Y / d X+k \Pi_{0} d Y / d X=0
$$

where $\Pi_{X}=P+(X+Y) P^{\prime}-\bar{W}_{t}$ and $\Pi_{Y}=P+(X+Y) P^{\prime}-T_{Y^{\prime}} \quad \Pi_{0 Y}=P_{0}+Y P_{0}^{\prime}-T_{Y}$ are both positive because the foreign firm is producing a less than optimal output for exports due to the VER. Since $d Y / d X<0$, the last two terms in condition (17) are negative, thus we obtain $\Pi_{X}>0$; that is, the foreign firm is underinvesting in the host country, contrarily to the claim of quid pro quo DFI (overinvesting).

\section{An Extension: A Two Stage Game}

In this section, we study a two stage game. In the first stage, the foreign firm determines the amount of DFI and the union determines the level of lobby simultaneously; in the second stage, they bargain for the wage rate. Here DFI is not of the quid pro quo type, since the foreign firm is not a firstmover. We obtain similar results as in the previous section that DFI increases union lobbying.

Since in this section, the game structure is the same as in the previous one except in the first stage, equations (1) to (10) are applicable. We only need 
to solve the problem for the first stage.

For the foreign firm, substituting the negotiated wage into (1) to obtain

$$
\text { II }=(1-K) \bar{\Pi}+\Pi_{0}
$$

where $\bar{I}$ is given in (9). Differentiating (18) with respect to DFI yields the firm's best response $\mathrm{X}$ as a function of lobbying $\mathrm{L}$

$$
\bar{\Pi}_{X}=P+(X+Y) P^{\prime}-\bar{W}=0
$$

By total differentiation of condition (19) and canceling $\bar{\Pi}_{Y X}=\bar{\Pi}_{X X}$ on both sides, we obtain $\mathrm{dL} / \mathrm{dX}=-1 / \mathrm{Y}_{\mathrm{L}}>0$.

Similarly, the union's utility is given by (9). The first order condition of utility maximization is given by (10), which is the best response of union lobby $L$ as a function DFI X. Totally differentiating (10) yields

$$
d L / d X=-\theta Y_{L} \bar{\Pi}_{x x} / \bar{\Pi} U_{L L}>0
$$

where $\bar{\Pi}_{x X}=\Pi_{X X} /(1-K)<0, U_{L L}<0$ due to the concavity of the profit and utility functions.

\section{Conclusions}

By introducing resource-using lobbying into the labor union's utility function and by endogeneizing the wage rate, this paper shows that domestic protectionist pressure increases as a resuit of DFI. This result is obtained under very general demand conditions and with the same game structure as the existing literature.

In order to highlight our points, we have abstracted from incorporating fixed costs and capital costs of DFI. Smith (1987) studies how fixed costs can affect a firm's decision to go multinational. Dinopoulos (1992) includes capital cost of DFI. He shows results are robust in the context of quid pro quo DFI. We have also abstracted from modeling the host country government in actively 
pursuing policy objectives. One could incorporate a government that maximizes a welfare function. It is doubtful that such complications would change the qualitative results of the present paper, as long as union lobby plays a significant role. 
Appendix A

This appendix proves that condition (13') is negatively signed under general conditions.

$$
\begin{aligned}
& \text { Let } P=a-(X+Y)^{i}, \quad P_{0}=a-Y^{i} \quad(a>0, \quad i=1,2, \ldots, n) \text { Then } \\
& \Pi=(1-K)\left\{\left[a-(X+Y)^{1}-\bar{W}\right] X+\left[a-(X+Y)^{1}\right] Y-T\right\}+K\left[\left(a-Y^{1}\right) Y-T\right] \\
& \Pi_{0}=\left(a-Y^{i}\right) Y-T
\end{aligned}
$$

Differentiating the above with respective variables yields

$$
\begin{aligned}
& \Pi_{X}=(1-K)\left\{a-\bar{W}-(i+1)(X+Y)^{i}\right\} \\
& \Pi_{X X}=(1-K)\left\{-i(i+1)(X+Y)^{i-1}\right\} \\
& \Pi_{Y}-\Pi_{O_{Y}}=(1-K)(i+1)\left\{-(X+Y)^{1}+Y^{i}\right\}
\end{aligned}
$$

Substituting (a1)-(a5) into condition (13') and rearranging yields

$$
\Delta=-(i+1)\left\{(X+Y)^{i-1} \Delta_{1}+(a-\bar{W}) \Delta_{2}\right\}
$$

where $\Delta_{1}=(X+Y)^{i+1}-[(i+1) X+Y] Y^{i}, \Delta_{2}=Y^{i}+(X+Y)^{i-1}[(i-1) X-Y]$. It is easy to show that for $\mathrm{I}=1,2, \ldots, \mathrm{n}, \Delta_{1}>0, \Delta_{2} \geq 0$, if $X>0, Y>0$. For instance, for $i=1, \Delta_{1}=X^{2}, \Delta_{2}=0$; for $i=2, \Delta_{1}=X^{2}(X+3 Y), \Delta_{2}=X^{2}$. Thus, condition (a6) and hence condition (13') are negatively signed. 


\section{References}

Bergsten, F., T. Horst and T. Moran, American Multinationals and American Interests, the Brookings Institution, Washington, D.C., 1978.

Bhagwati, Jagdish N., "Protectionism: Old Wine in New Bottles," Journal of Policy Modeling, July 1985, 23-34.

Bhagwati, Jagdish N., Richard A. Brecher, Elias Dinopoulos and T.N. Srinivasan, "Quid Pro Quo Foreign Investment and Welfare: A Political-EconomyTheoretic Model," Journal of Development Economics, 1987 pp 127-38.

Bhagwati, Jagdish N., Elias Dinopoulos and Kar-Yiu Wong, "Quid Pro Quo Foreign Investment," American Economic Review, Papers and Proceedings, May 1992.

Brander, James A. and Barbara J. Spencer, "Unionized Oligopoly and International Trade Policy," Journal of International Economics, 1988, 24, $217-234$.

Brecher, Richard and Carlos Diaz Alejandro, "Tariffs, Foreign Capital and Immiserizing Growth," Journal of International Economics, 1977, 317-322.

Brock, W. and S. Magee, The Economics of Special Interest Politics: The Case of the Tariff," American Economic Review, 1978, 68, 246-250.

Clark, A. and A., Oswald, "Trade Union Utility Functions: A Survey of Union Leaders' Views," Industrial Relations, 1993, 32, 3, 391-423.

Dinopoulos, Elias, "Quid Pro Quo Foreign Investment," Economics and Politics, $1989,145-160$.

Dinopoulos, Elias, "Quid Pro Quo Foreign Investment and VERs: A Nash Bargaining Approach," Economics and Politics, 1992, 4, 43-60.

Dinopoulos, Elias and Kar-yiu Wong, "Quid Pro Quo Foreign Investment and Government Intervention," in K. Koekkoek and C.Mennes (eds.), International Trade and Global Development, Routledge, 1991.

Findlay, Ronald W. and Stanislaw H. Wellisz, "Endogenous Tariffs, the Political Economy of Trade Restrictions and Welfare," in Jagdish N. Bhagwati (ed.), Import Competition and Response, Chicago University Press, 1982, 223-234.

Holmstrom, Bengt, "Moral Hazard and Observability," Bell Journal of Economics, $1979,74-91$.

Mayer, W., "Endogenous Tariff Formation," American Economic Review, 1984, 970985.

McDonald, Ian M. and Robert Solow, "Wage Bargaining and Employment," American Economic Review, 1981, 71, 896-908. 
Mezzetti, Claudio and Elias Dinopoulos, "Domestic Unionization and Import Competition," Journal of International Economics, 1991, 79-100.

Nelson, D. R., "The Political-Economy of U.S. Automobile Protection," NBER working paper no. 4746, 1994.

Okamura, Makoto, "Endogenous Tariff Formation and Direct Foreign Investment: A General Equilibrium Analysis," Discussion paper series F-067, Tezukayama University, 1993.

Oswald, A.J., "The Economic Theory of Trade Unions-An Introductory Survey, Scandinavian Journal of Economics, 1985, 87, 160-193.

Pemberton, James, "A 'Managerial' Model of the Trade Union," The Economic Journal, 1988, 98, 755-771.

Smith, Alasdair, "Strategic Investment, Multinational Corporations and Trade Policy," European Economic Review 31, 1987, 89-96.

Wong, Kar-Yiu, "Optimal Threat of Trade Restriction and Quid Pro Quo Foreign Investment," Economics and Politics, 1989, Volume 1, 277-300.

Zhao, Laixun, "Cross-Hauling Direct Foreign Investment and Unionized Oligopoly," 1994, forthcoming in European Economic Review. 


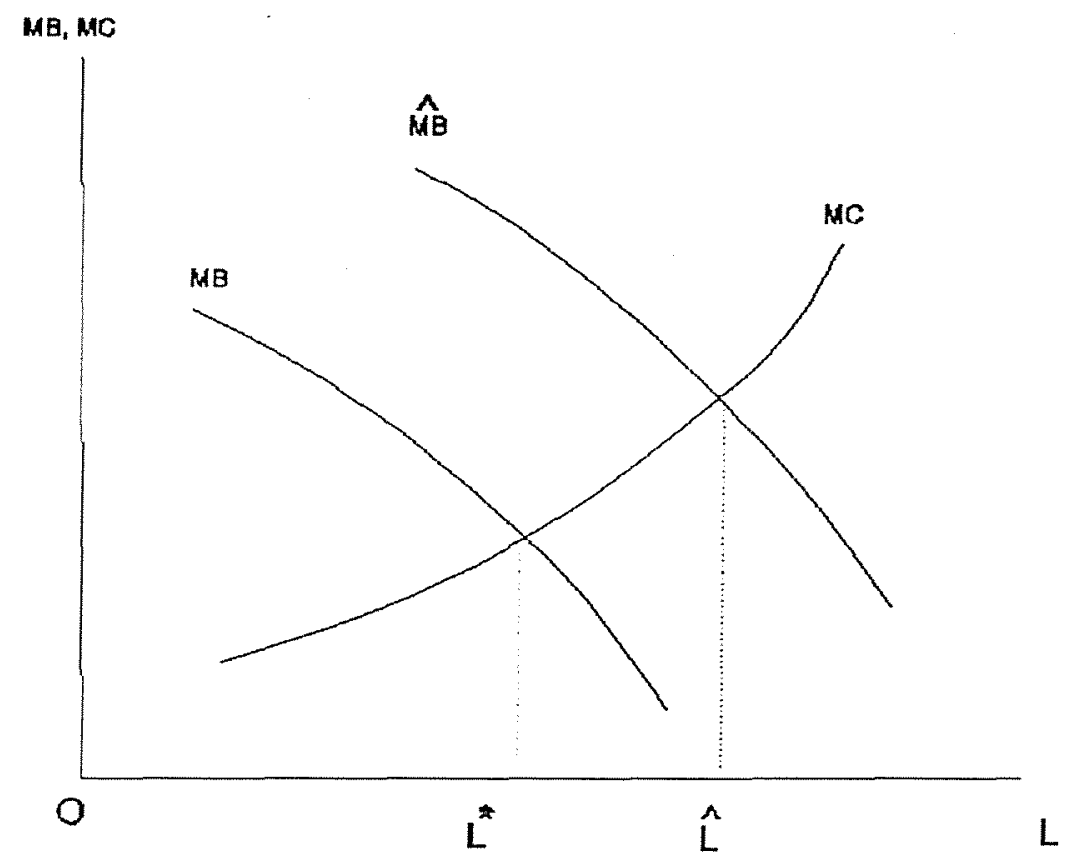

Figure 1 Complementarity of DFI and Lobbying 
This Discussion Paper Series is published by the Institute of Economic Research and integrates two old ones published separately by the Department of Economics and the Department of Commerce.

Discussion Paper Series
Institute of Economic Research
Otaru University of Commerce

No.

Title

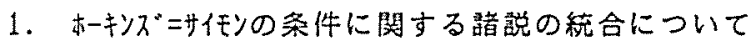

2. Motivation and Causal Inferences in the Budgetary Control

3. Проблемы управления рабоче н силоина предлриятиях Дальнего Востока(социологнческие аспекты)

4. Dynamic Tax Incidence in a Finite Horizon Kodel

5. Business Cycles with Asset Price Bubbles and the Role of Honetary Policy

6. Continuous Double-Sided Auctions in Foreign Exchange Markets

7. The Existence of Ramsey Equilibrium with Consumption Externality

8. Money, Neutrality of Consumption Taxes, and Growth in Intertemporal 0ptimizing Hodels

9. Product Returns in the Japanese Distribution System:A Case Study of a Japanese Wholesaler's Return Reduction Efforts

10. Dynamics, Consistent Conjectures and Heterogeneous Agents in the Private Provision of Public Goods

11. Intra-Industry Investment and Imperfect Markets A Geometric Approach in Simple General Equilibrium

12. Sit-Down to Split:Flint GM Yorkers in 1937-1939

13. The Complementarity between Endogenous Protection and Direct Foreign Investment

Discussion Paper Series

Department of Economics

Otaru University of Commerce

No.

Title

1. Monetary Policy in a Model of International Trade with a Sector Sticky Wage Rate

2. Export Credit Insurance

3. Asset Trading in an Overlapping-Generations Model:Efficiency of Competitive Equilibrium

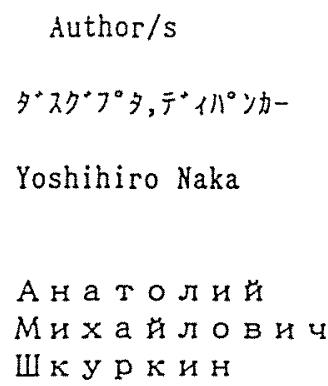

Date

Jul. 1992

Aug. 1992

Nov. 1992

Jun-ichi Itaya

Jan. 1993

Hiroshi Shibuya

Jun. 1993

Ryosuke riada

Aug. 1993

Sadao Kanaya

Sep. 1993

\& Tomoichi Shinotsuka

Jun-ichi I taya

Nov. 1993

Jeffery Alan Brunson

Mar.1994

Jun-ichi Itaya

Jun. 1994

\& Dipankar Dasgupta

Laixun thao

oct.199.4

Satoshi Takata

Dec. 1994

Laixun Zhao

Feb. 1995

\begin{tabular}{ll}
\multicolumn{1}{l}{ Author/s } & Date \\
Takashi Fukushima & Feb.1985 \\
G Hideki Funatsu & \\
Hideki Funatsu & Feb.1985 \\
Renji ragamoto & Oct.1985
\end{tabular}


4. Asset Trading in an Overlapping-Generations Model with Production Shocks

5. Immiserizing Investment in a Vertically Related International Trade

Masao Satake

Mar.1986

6. Dynamic Tax Incidence in a Two-Class Economy

Jun-ichi Itaya

May 1980

7. A Three Factor Model of International Trade with Minimum Wage Rates

Hideki Funatsu

Kay 1980

8. A Note of the Maximum Number of Firms with Equal Market Share in a Quantity Setting Supergame

9. Tax Incidence in a Tro-Sector Growing Economy with Perfect Foresight

10. Two Kinds of Information in Price Search

Masaru Uzawa

Nov. 1986

Jun-ichi Itaya

May 1987

Kaoru Endo

Aug. 1987

\& Teruya Nagao

Jun-ichi Itaya

Oct. 1987

11. On the Hedging and Investment Behavior of the Competitive Firm under Price Uncertainty

12. Tax Incidence in a Tro-Sector Growing Economy with Perfect Foresight:Long-Run Analysis

Jun-ichi Itaya

$\operatorname{Mar} .1988$

13. Comparative Statics for the Private Provision of Public Goods in a Conjectural Variations Model with Heterogeneous Agents

Dipankar Dasgupta

Mar. 1991

\& Jun-ichi Itaya

Jun-ichi Itaya

Mar.1991 Adjustemnt Costs

15. Using the Correct Economic Interpretation to Prove

Dipankar Dasgupta

Jul.1991 the Hawkins-Simon-Nikaido Theorem:One Hore Note

16. Transversality Condition in Infinite Time Horizon Concave Problems

Discussion Paper Series

Department of Commerce

Otaru University of Commerce
No.
Title
Author/s
Date

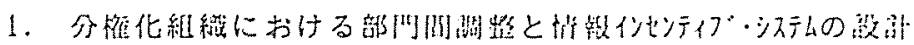
HEN
\& 神野好文
Apr. 1985

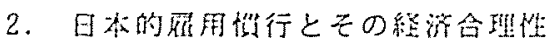
州上正
\& 别野能文
May 1989

Institute of Economic Research, Otaru University of Commerce

3-5-21, Midori, Otaru, Hokkaido 047, Japan Tel.0134-23-1101

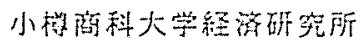

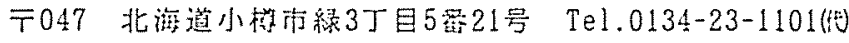

